\title{
Difficulties in the industrial introduction of new effective hydrodesulfurization catalysts in the Russian Federation
}

\author{
R.R. Konoplin, N.K. Kondrasheva \\ Department of Chemical Technology and Processing of Utilities, Faculty of Raw Material \\ Processing, St. Petersburg Mining University, Russia
}

\begin{abstract}
The article presents bibliographic knowledgeof the worldscaleinventions that formed the basis ofHDS-catalysts for the development of variousoil products. Extensive studies were conductedon optimizationof carrier properties, active-phase chemical-mass composition, and basictechnological parameters of transformation of initial components into active six-sided $\mathrm{MoS}_{2}$ groups which are decorated by $\mathrm{CoS}_{2}$ molecules, involving stages of desulfurization ofoxide formsof the catalyst. Differences in the microstructure of $\mathrm{Al}_{2} \mathrm{O}_{3}$ supportsderived from aluminum hydroxide of various genesis are described. Comparative possibilitiesof binding properties of aluminum hydroxide raw materials in laboratory tests and molding ofwaterpeptidized pastesare presented.
\end{abstract}

\section{Introduction}

In the oil refining sphere, the catalytic hydrotreating processes, or the so-called refining of crude raw materials, are of paramount and fundamental importance, since they significantly reduce the content of the following out-of-tolerance impurities in the products (sulfur, nitrogen, oxygen, and the metals $\mathrm{V}, \mathrm{Ni}$ ). However, due to the fact that the quality of oil produced in the world is constantly deteriorating, it is necessary to intensify hydrotreating processes and introduce highly effective catalysts (high activity, selectivity, and long cycle life).

The hydrodesulfurization (HDS) process is characterized by two parallel reactions: hydrogenolysis of organic sulfur compounds into hydrogen sulfide and hydrogenation of unsaturated hydrocarbons(linear or cyclic) $[1,2]$. The HDS process of light oil fractions takes place ata relatively low temperature $\left(\mathrm{T}=350-450^{\circ} \mathrm{C}\right)$ and can proceed at a low partialhydrogen pressure. Increasing the temperature and pressure allows to direct the reactions to alkane cracking andincreasethe sulfur yield withinheteroatomic compounds such as dibenzothiophene.

The conventionalinitialstep of the HDS process on the catalyst is the destruction of the $\mathrm{C}-\mathrm{S}$ bond and the addition of hydrogen to the sitesof destruction in the molecule.

The compositions of the active components HDS catalysts (Mo or W combined with $\mathrm{Ni}$ or Co)have beenwidely studied and patented since the middle of the last century. Mo and $\mathrm{W}$ oxides are semiconductors with p-conductivity, and their activity in redox reactions is due to the presence of free electrons on the surfaceof microcrystals, which are capable of 
chemisorption and homolytic decomposition of organic molecules. Molybdenum sulfides are also semiconductors and their conductivity causesthe cleavage reactions of C-S, C-N, and $\mathrm{C}-\mathrm{O}$ bonds in heteroorganic compounds.

However, Mo and $\mathrm{W}$ are significantly less active in hydrogenating compared toNi and Co. Therefore, the addition of these elements and their combination in the catalyst with Mo and $\mathrm{W}$ provides destruction of the organic molecule and hydrogenation in free bonds, i.e. bifunctional properties.

For the effective catalytic process, it is necessary to develop the number of active centers (potential points of contact of organic molecules with them) and transport the access of organic molecules to them.

The implementation of the last two conditions canbe achieved by using a supportthatallows reducing the content of the active component to anoptimum minimum due to the thinlayer distribution of $\mathrm{Mo}(\mathrm{W})-\mathrm{Ni}(\mathrm{Co})$ metals and the required porous structuring. In this case,during the movement of reagents to the active centers of the catalyst, diffusion resistance will be completely absent or minimized.

It took many years to develop HDS catalysts as thefinal material to be loaded into the reactor. Research to improve catalyst technology and thinstructuresis ongoing worldwide and widespread.

Analysis ofpublications on this topic allows us to trace the world's developments and identify significant properties of the best modern industrial catalysts, as well as opportunities for their further improvement.

\section{Teoretical part}

\subsection{Support}

In the catalysts industry, reducingproduction costs while increasing their activity is a toppriority objective set for developers. This is possible with mesoporous active supports such as aluminum and silicon oxides. The following properties are required for HDS catalyst supports:

1. High mechanical strength to reduce catalyst wearduring operationasdefined by GOST 21153.2-84[3,4,5,6,7].

2. Large surface area for the acceleration of active phases in the interaction with organosulfur reagents $[3,8]$.

3. The availability of acid sides to improve active metals dispersion $[3,7,9]$.

4. Reducing the strength of the metal-support bond to facilitate the reduction and sulfidation of the active phases.

The research of the support properties has started over 40 years ago. In earlier works, dozens of commercialAl $\mathrm{O}_{2} \mathrm{O}_{3}$ support grades were tested:Ketjen SK-300 with $\mathrm{S}_{\mathrm{BET}}=192 \mathrm{~m}^{2} / \mathrm{g}$ [10], Girdler T-126 with $\mathrm{S}_{\mathrm{BET}}=188 \mathrm{~m}^{2} / \mathrm{g}$ [11], $\gamma-\mathrm{Al}_{2} \mathrm{O}_{3}$ Degussa with $\mathrm{S}_{\mathrm{BET}}=105 \mathrm{~m}^{2} / \mathrm{g}$ [12], JCR-AlO-7 with $\mathrm{S}_{\mathrm{BET}}=180 \mathrm{~m}^{2} \mathrm{~g}, \gamma-\mathrm{Al}_{2} \mathrm{O}_{3}$ Axens withS $\mathrm{BET}_{\mathrm{BET}}$ from 90 to $300 \mathrm{~m}^{2} / \mathrm{g}[13,14]$. Along with those, laboratory auxiliary support samples based on different types of aluminum hydroxides [15] and various molding methods (extrusion and dropping) with the addition of various components $\left(\mathrm{SiO}_{2}, \mathrm{TiO}_{2}, \mathrm{CeO}_{2}, \mathrm{ZrO}_{2}\right)$ [16]were obtained. The range of structural properties was the following: $\mathrm{S}_{\mathrm{BET}}$ from 100 to $640 \mathrm{~m}^{2} / \mathrm{g}$, and total pore volume from 0.16 to $2.71 \mathrm{~cm}^{3} / \mathrm{g}[17,18,19,20,21,22]$. The tested aluminum hydroxides were derived from precipitated sodium aluminates, alumina obtained using sol-gel technology from Catapal A Pural SB1 aluminum-organic compounds, and the product of gibbsite thermochemical activation. 
According to the activity test results of Mo-Ni and Mo-Co catalysts samples obtained from the described supports, it was concluded that $\gamma-\mathrm{Al}_{2} \mathrm{O}_{3}$ supports with $\mathrm{S}_{\mathrm{BET}}$ from 240 to $340 \mathrm{~m}^{2} / \mathrm{g}$ and total pore volume from 0.55 to $0.80 \mathrm{~cm}^{3} / \mathrm{g}$ allows $90-98 \%$ of sulfur removal efficiency.
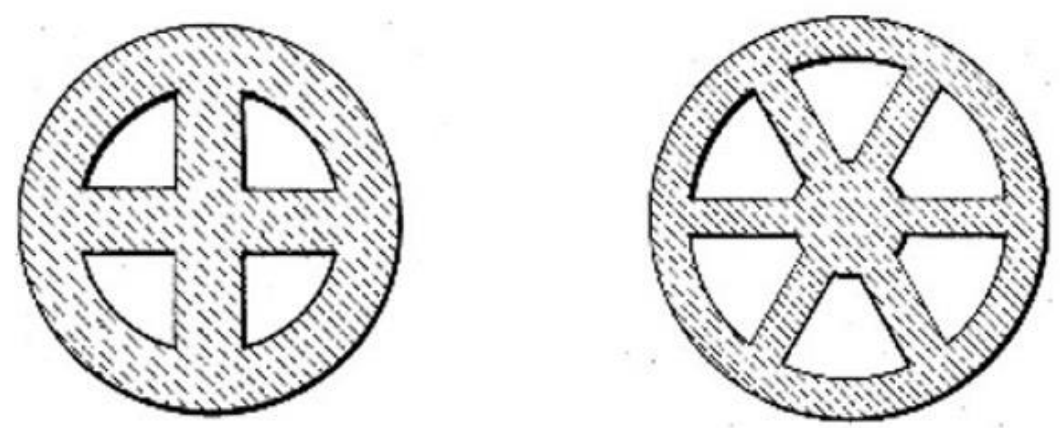

Fig. 1. Catalyst support forms of extrudates (Carmo J. Pereira \& Hegedus, 1985).

However, the difficultyin specifying alumina as a feedstock to supports large-scale production, in addition to the demand for high structural characteristics, is all

about binding properties and formability. To increase the geometric contact surface of liquid hydrocarbons contact surface with the surface of the catalyst, the variousforms of granulated spheres, cylinders, rings, and extrudates of complex shapes with low packed density were designed. In this case, it was necessary to ensure the formation of granules with external diameter $\leq 6.5 \mathrm{~mm}, \mathrm{~S}_{\mathrm{BET}} \geq 100 \mathrm{~m}^{2} / \mathrm{g}, \sum \mathrm{V}_{\text {pores }} \geq 0.5 \mathrm{~cm}^{3} / \mathrm{g}$, and with shape stability in the subsequent stages of metal activation and heat treatment [23]. The shapes of the granules are presented in Figure 1.

The configuration of granulesin the form of a fan rotor initiated localturbulenceof the gas-liquid mixtures, significantly increasing the mixing of reactants and their contact with the catalysts. However, the commercialproduction of these forms of supports was possible only using the low-surface raw materials, and as a result, led to low support properties, which are the following: $\mathrm{S}_{\mathrm{BET}} \leq 50 \mathrm{~m}^{2} / \mathrm{g}, \sum \mathrm{V}_{\text {pores }} \leq 0.3 \mathrm{~cm}^{3} / \mathrm{g}$. Such supports would require the application of an intermediate layer followed by activation of this layer with active catalyst components. This production method is multi-stage, and therefore more expensive.

Demetallization and desulfurization reactions occur in the HDS processes of petroleum products and limit each other depending on the orderof interphase diffusion. For these types ofreactions, the required granule size is determined according to the maximum conversion values for both types of reactions with the $\mathrm{t} / \mathrm{d}$ ratio ranging from 0.10 to 0.30 , and the most desirable value equals 0.15 . The values are presented in Figure 2.

The " $t$ " values are the wall thickness of theextrudate and " $\mathrm{d}$ " is the diameters of the granules. The value "a" is the amount of catalyst-conversion relationships. The "b" values are the ratios ofthe geometric surface of the catalysts to the reactor volume. The intercept point of "a" and "b" at $\mathrm{t} / \mathrm{d}$ ratio equal 0.15 corresponds to the optimal extrudate with a 1.59 $\mathrm{mm}$ diameter and a wall thickness of $0.24 \mathrm{~mm}$. These parameters were usedinthe commercial productionof HDS catalysts. To increase the geometric treatment of the catalyst surface, a complex shape of tri- and quadralobeextrudates was used during the formation [23].

Along with optimizing the catalyst shape and grain size, great importancewas givento the support porous structure; it was noted that amonodisperse with a predominant pore size of 7-10 nmwas the most desirable. However, there is another approach with apreference for abidisperse structure with pores of 2-5 nm (micropores) and 40-50 nm (mesopores), as well as intermediate pore sizes to connectmicro- and mesopores [23]. 


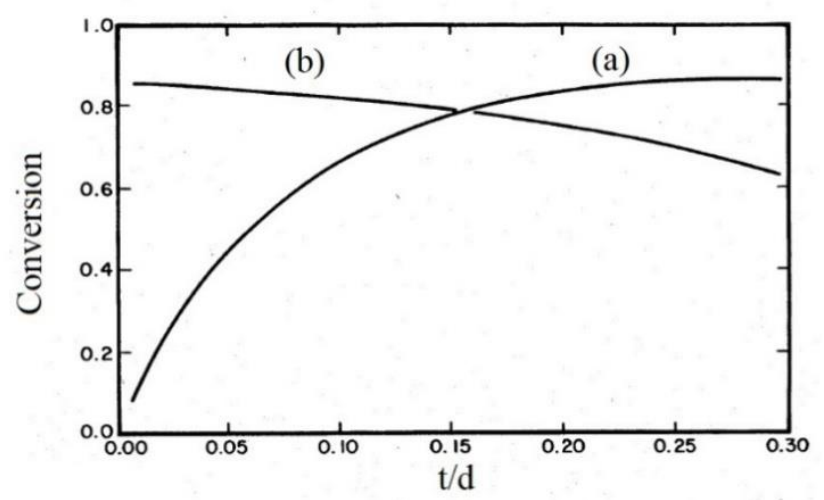

Fig. 2. Catalyst extrudates optimization treatment (Carmo J. Pereira \& Hegedus 1985).

Micropores, which provide a high surface area $\left(250-300 \mathrm{~m}^{2} / \mathrm{g}\right)$, are the main source of concentration of active catalyst centers, while the mesopores provide access to thereagents.

The formation of supports with a predetermined and controlled texture in the technological process is the most problematic aspect of the HDS catalyst industrial production.

It is also necessaryto optimize the acid-base properties of the $\mathrm{Al}_{2} \mathrm{O}_{3}$ surface or, in other words, to make four- $\left(\mathrm{Al}^{\mathrm{IV}}\right)$ and five-fold $\left(\mathrm{Al}^{\mathrm{V}}\right)$ acid centers that could catalyze several chemical reactions. This problem can be solved in the process of thesupport body structure development. Such optimization can be implemented in the initial part of the alumina genesis. Also, the technological methods, such as adding promoters and co-components to the raw materials and the temperature regime, mustbe taken into account.

From this point of view, variousnanostructured oxide materials and zeolites represent a particularly importantstarting material for the formation of new porous systems based on thealuminum oxide matrix with special properties (largepore volumes, surfaces, and high strength characteristics). Such supportsmake it possible to increase the concentrations of base metals, as well as the number of available promoters (steric and acidic) fordispersion modification [22].

The use of chelating agents or additives such as phosphorus and boron $[24,22,16]$ increases the acidity of the support, at the same timeit changes the distribution of hydroxyl groups on the surface, reduces the interaction of active metals with the support, leads to the multilayer structure [Co Mo S] - or [Ni Mo S] formation, and optimizes the efficiencyof desulfurization.

Attempts were made to introduceboron and phosphorus in the industrial support structure $[25,26,24]$, consequently, the acidity of the materials was increased, and the trend of reactions towards cracking, isomerization, and hydrogenolysis was noted.

For a long time, the role of carbon in HDS catalysts was a contentious issue: on the one hand, carbonization causes deactivation, and on the other, the presence of carbonduring desulfurization of the compounds leads toimproving catalyst activity [27]. The effect of carbon was studied on industrial catalysts. The supports $\left(\gamma-\mathrm{Al}_{2} \mathrm{O}_{3}\right.$ with $\left.\mathrm{S}_{\mathrm{BET}}=220 \mathrm{~m} / \mathrm{g}\right)$ were impregnated with $\mathrm{C}_{20}$ gas oil before activation (by applying $12.3 \% \mathrm{wt}$. Mo and $3 \% \mathrm{wt}$. Co), followed by drying and coking. After sulfidation in a stream of $\mathrm{H}_{2} \mathrm{~S}+\mathrm{H}_{2}$, an increase in thiophene desulfurization activity of at least $30 \%$ was observed [27]. It was assumed that during the activation of the catalyst, the resulting atomic ensembles migrate tothe surface, while carbon,present in the amount of $2-4 \%$ wt., prevents this migration by limiting layer growth in $\mathrm{MoS}_{2}$ crystals andstabilizes the texture of the catalyst in general.

Nikul'shin [13] studied the effect of surface carbon in the support.The support was an $\mathrm{Al}_{2} \mathrm{O}_{3}$ matrix with a carbon coating obtained by pyrolysis (in $\mathrm{N}_{2}$ at $600^{\circ} \mathrm{C}$ ) of the final 
component impregnated with a mixture of isopropanol andglycerin. Tests of Co-Mo and Ni-Mo catalysts in HDSfrom thiophene and dibenzothiophene on carbonized supports showed an advantage over similar tests on a plain $\mathrm{Al}_{2} \mathrm{O}_{3}$ support. The highest activity was obtained with a surface carbon content of $1.2-2.3 \% \mathrm{wt}$. The increased activity of the catalysts on carbonized supports was explained by a decrease in the interaction strength of the active phase ensemble (Co [Ni] MoS) with the support and the ability of supported carbon to accumulate hydrogen while facilitating its delivery to the centers of the active phase. Another function of carbon in such catalysts, according to the authors, is to change the morphology of the active phase. With an increase in carbon content above $4 \% \mathrm{wt}$, the catalyst activity decreased. It was suggested that the optimal carbon concentration on each support should be individual, depending on the size of its surface to obtain the required coating density.

Recently, there is high interest in using more stable crystalline and phase structures of $\mathrm{Al}_{2} \mathrm{O}_{3}$ as supports that were not studied in previous years. At high temperatures, tetragonal $\gamma-\mathrm{Al}_{2} \mathrm{O}_{3}$ supports were obtained due to the intergrowth of the initial $\gamma-\mathrm{Al}_{2} \mathrm{O}_{3}$ and $\delta$ $\mathrm{Al}_{2} \mathrm{O}_{3}$ pseudocubiccrystals form. On these support samples, the catalysts with the same atomic density of molybdenum, promoted by cobalt, were prepared under different conditions and 4.6 - dimethyldibenzothiophene (4.6 - DMDBT) wastested in the model hydrodesulfurization reaction.A weaker interaction of the active CoMoSphase with $\delta$ $\mathrm{Al}_{2} \mathrm{O}_{3}$ support and higher activity was found, apparently, due to the formation another, preferable for the reaction, energy model of active centers [14].

\subsection{Catalyst}

The development of modern commercialHDS catalysts and the determination of technological methods and parameters for their production was explained in details in a large number of different studies. In [28], the specificationof the active phase of the chemical composition and its mass content on the support was studied.[29] in their works studied different methods of applying the active phase to the supports. In $[30,31,32,33]$, the influence of promoters of various nature (steric, acidic) on the formation of the active phase and the determination of their quantity and the methods of introducing them into the catalyst were investigated.

As a result, the main components of theactive partof the catalyst,Mo (W) 8-15\% wt. and $\mathrm{Co}(\mathrm{Ni}) 3-5 \%$ wt., were found to be non-alternative. $\gamma-\mathrm{Al}_{2} \mathrm{O}_{3}$ molybdenum catalysts with maximum dispersion are catalysts with monolayer coating of the support surface. However, there are two types of monolayers; the former monolayer corresponds to the geometric surface coating,and in the later monolayer molybdenum occupies all chemical surface vacancies. The formation reaction of a Mo bond with $\mathrm{Al}_{2} \mathrm{O}_{3}$ proceeds through $\mathrm{OH}$ groups, and it was determined thatthe maximum dispersion is achieved at $0.12 \mathrm{~g}$ of $\mathrm{MoO}_{3} / 100 \mathrm{~m}^{2} \gamma$ $\mathrm{Al}_{2} \mathrm{O}_{3}$, which is $\sim 74 \%$ of the geometric monolayer. Theamount of Mo exceeding this value remains as a free crystalline phase [12].

The conventional precursors of Mo and $\mathrm{W}$ are water-soluble ammonium paramolybdates and tungstates, while $\mathrm{Co}$ and $\mathrm{Ni}$ are crystalline nitric acid hydrates.

The predominant method of applying the active components onthe support is impregnation with incipient moisture followed by drying and heat treatment of the contact mass at temperatures $\left(110-120^{\circ} \mathrm{C}\right)-500^{\circ} \mathrm{C}[18,8,16]$.

The use of various high-resolution analytical methods in the combined studies of the surface structures of HDS catalysts (XPS, HRTEM-EDX, EXAFS, DRS - UV-Vis) allows to evaluate the valence state of molybdenum, the sulfur distribution, and to determine the elementary active complex structure, which is the hexagonal layer of the $\mathrm{MoS}_{2}$ nanocluster with Co atoms at the edges. This model of active cells is characteristic for type I and type II 
catalysts definedby foreign developers forindustrial hydrotreating catalysts. The type II catalysts are more active than type I due to the multilayer structure of $\mathrm{MoS}_{2}$ hexagens, which are weakly bonded through oxygen [Mo-O-Al] to the support [18]. In type I catalysts this bond is stronger, as a result, the sulfidation process proceeds are less efficient, and this reduces the final activity.

The dispersion of the active phase and the interactiondeterioration with the support are promoted by the chelating agents present,such as citric acidandother organic complexing agents and acid additives, such as boron and phosphorus [34,35,36].

Type II commercial catalysts are produced using co-impregnationwith nitrile triacetic acid, which, at the stage of sulfidation, affects the rate of Nisulfurization and decreases it in relation to Mo, which, as a result, reduces $\mathrm{NiS}_{2}$ aggregation in reaction processes [37].

The final technological sulfidation stage, where the active surface structure is formed, can be carried out in the industrial reactor in several ways: gas-phase, liquid-phase, or combined. The wayis selected according to the equipment capabilities atthe industrial unit. Gas-phase sulfidation is carried out in a stream of hydrogen with the addition of $5-15 \%$ vol. $\mathrm{H}_{2} \mathrm{~S}$ with a gradual increase in catalyst temperature to $400-500^{\circ} \mathrm{C}[24,25,16]$. The liquidphase process runs with a solution of dimethyl sulfide in straight distillation gas oil with a sulfur content of $3.7 \%$ wt. in hydrogen with a gradualtemperature rise from 30 to 320 $350^{\circ} \mathrm{C}$ within 20 hours [37]. After the sulfidation step, a reagent is supplied to the catalyst.

With the expansion of the Russian Federation into the globalmarket, the requirements for the quality of petroleum products in terms of sulfur content (less than $10 \mathrm{ppm}$ ), octane, and cetane numbers have significantly increased. The domestic catalysts could not meet the international requirements; thus, the predominant consumption of imported catalysts is taking place. The total load with imported catalysts at the 40 largestrefinery plants is about $80 \%$.

Currently, the leading developers and suppliers of HDS catalysts in the Russian Federation are the following international companies: Axens, Exxon Mobile, and Albemarle. Their productsdemonstrate high hydrotreatment activity (up to 99\%), long service life, and maintaining the initial performance after regeneration.

The macro properties of the described catalysts are as follows: $3.5-4.0 \% \mathrm{Co} ; 13-15 \%$ $\mathrm{Mo} ; \mathrm{S}_{\mathrm{BET}}$. $=245-265 \mathrm{~m}^{2} / \mathrm{g}$; and the phase composition of the support is $\gamma-\mathrm{Al}_{2} \mathrm{O}_{3}$. However, the difference between imported and domestic catalysts is the fineness of complex-shaped (tri- and quadralobe, Figure 3a) granules with a 1.3-1.8 mm diameter.

According to the high quality of fine-grained complex-profile extrudates, the basis is pseudo-boehmite and boehmite aluminum hydroxides, which, in fact, and are described in hydrodesulfurization catalysts patents $[11,29]$.

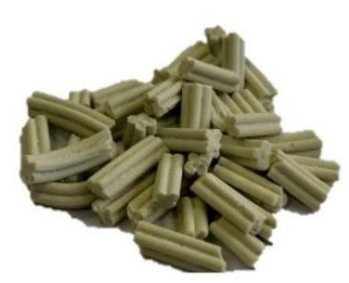

a

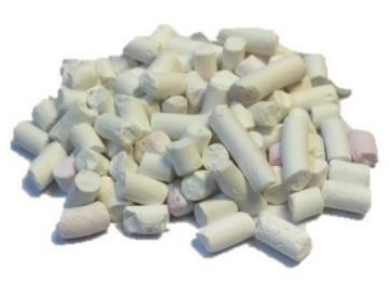

b

Fig. 3.Catalyst support forms of extrudates:a - modern catalysts, b- domestic catalysts.

In the USSR, the pseudo-boehmite structure raw aluminum hydroxide derived from the ammonium nitrate deposition was produced at the only enterprise "AZOT" (now OAO 
"Catalyst") in Dneprodzerzhinsk (Ukraine) and was intended for consumption in other than oil industries.

For the oil industry, catalysts in the Russian Federation in the form of extruded support have traditionally been produced and currently are manufactured based on deposited alumina of bayerite-boehmite phase composition. This $\mathrm{Al}_{2} \mathrm{O}_{3}$ support is a 2.8-3.8 mm cylinder (Figure $3 \mathrm{~b}$ ) with varying limitations of texture properties, and undesirable sodium impurities.

At present, in accordance with the program of import substitutionin the oil industry, the issue of production of domestic competitive new-generation HDS catalysts production is urgent. A prerequisite for catalystmodernization is theuse of domestic industrial aluminum hydroxide feedstock for production of the catalyst support base.

The available alumina raw materials are the following:

- Domestic production:

1. aluminum hydroxide derived using the aluminum-nitrate high and lowtemperature sedimentation with 60-70\% wt. moisture; Promkataliz, Ryazan;

- Imported raw materials:

2. aluminum hydroxide derived using the acidic-nitrate sedimentation, Katalizator, Ukraine;

3. aluminum hydroxide derived using the aluminum alkoxides hydrolysisPural SB1, SASOL, Germany.

\section{Results and discussion}

The phase composition was conducted using the XRD and DTA analyzes.It was found that the set of samples \# 2 and 3 have the purest phase composition.Only sample №3 contains a pseudo-boehmite phase with a small admixture of amorphous substance. The sample №3Pural SB1 also has a small amorphous fraction of totally well-crystallized boehmite. The aluminate precipitation alumina hydroxideis a bayerite-boehmite composition. The data is presented in Table 1.

Table 1.Alumina raw material phase composition.

\begin{tabular}{|c|c|c|c|c|c|c|}
\hline \multirow{2}{*}{$\begin{array}{l}\text { Alumina raw } \\
\text { material }\end{array}$} & \multicolumn{6}{|l|}{ Phase } \\
\hline & $\begin{array}{l}\mathrm{Al}(\mathrm{OH})_{3} \\
\text { Amor- } \\
\text { phous }\end{array}$ & $\begin{array}{l}\mathrm{Al}(\mathrm{OH}) \\
3 \\
\text { Gibbs- } \\
\text { ite }\end{array}$ & $\begin{array}{l}\mathrm{Al}(\mathrm{OH}) \\
3 \\
\text { Bayer- } \\
\text { ite }\end{array}$ & $\begin{array}{l}\mathrm{AlOOH} \cdot \mathrm{nH}_{2} \\
\mathrm{O} \\
\text { Poorly } \\
\text { crystallized } \\
\text { boehmite }\end{array}$ & $\begin{array}{l}\mathrm{AlOOH} \cdot \mathrm{nH}_{2} \\
\mathrm{O} \\
\text { Well } \\
\text { crystallized } \\
\text { boehmite }\end{array}$ & $\begin{array}{l}\mathrm{AlOOH} \cdot \mathrm{nH}_{2} \mathrm{O} \\
\text { Pseudoboehm- } \\
\text { ite }\end{array}$ \\
\hline $\begin{array}{l}\text { Aluminum- } \\
\text { nitrate sedi- } \\
\text { mentation }\end{array}$ & 6 & No & 15 & 79 & No & No \\
\hline $\begin{array}{l}\text { Acidic- } \\
\text { nitrate sedi- } \\
\text { mentation }\end{array}$ & 13 & No & No & No & No & 87 \\
\hline $\begin{array}{l}\text { Pural SB1 } \\
\text { SASOL } \\
\text { (Germany) }\end{array}$ & 5 & No & No & No & 95 & No \\
\hline
\end{tabular}

The comparative ability of alumina raw materials'binding properties is demonstrated in the process of laboratory testing during theobtaining and molding of pastes peptized only with water. The resultspresented in Table 2 show the agreement with the phase characteris- 
tics of hydroxides, once again confirming the advantages of pseudo-boehmite and the negative effect of the heterogeneous phase composition. That influences both formability and the strength properties of the porous anhydrous $\mathrm{Al}_{2} \mathrm{O}_{3}$ structure.

Table 2. Alumina raw material comparative analysis.

\begin{tabular}{|c|c|c|c|c|c|}
\hline \multirow[t]{2}{*}{$\begin{array}{l}\text { Alumina raw mate- } \\
\text { rial }\end{array}$} & \multirow{2}{*}{$\begin{array}{l}\text { Peptizing } \\
\text { agent - water } \\
\mathrm{g} \mathrm{H}_{2} \mathrm{O} / \mathrm{g} \\
\mathrm{Al}_{2} \mathrm{O}_{3}\end{array}$} & \multirow[t]{2}{*}{$\begin{array}{l}\text { Formability } \\
\text { evaluation }\end{array}$} & \multicolumn{3}{|c|}{$\begin{array}{l}\text { Cylinder pellets propertiesc } \mathrm{d}=4 \\
\text { mmafter } 500^{\circ} \mathrm{C}-3 \mathrm{~h} \text {. }\end{array}$} \\
\hline & & & $\begin{array}{l}\mathrm{S} \\
\mathrm{m}^{2} / \mathrm{g}\end{array}$ & $\begin{array}{l}\sum \mathrm{V}_{\text {por }} \\
\mathrm{sm}^{3} / \mathrm{g}\end{array}$ & $\begin{array}{l}\text { Strength } \\
\text { properties, } \\
\mathrm{kg} / \mathrm{sm}^{2}\end{array}$ \\
\hline $\begin{array}{l}\text { Aluminum-nitrate } \\
\text { sedimentation }\end{array}$ & 1,22 & $\begin{array}{l}\text { Low-ductile paste, } \\
\text { thixotropy, hard to } \\
\text { form }\end{array}$ & 200 & 0,88 & 12 \\
\hline $\begin{array}{l}\text { Acidic-nitrate sed- } \\
\text { imentation }\end{array}$ & 1,06 & $\begin{array}{l}\text { Solid paste, highly- } \\
\text { ductile, } \\
\text { very well-formed }\end{array}$ & 320 & 0,63 & 84 \\
\hline $\begin{array}{l}\text { Hydrolysis of alu- } \\
\text { minum } \\
\text { alkoxides }\end{array}$ & 1,23 & $\begin{array}{l}\text { Very solid, rubberlike, } \\
\text { translucid, well- } \\
\text { formed }\end{array}$ & 230 & 0,48 & 24 \\
\hline
\end{tabular}

\section{Conclusion}

According to the laboratory results, it was found that:

- The pseudo-boehmite phase provides the best formability properties of the paste during the extrusion process.

- Sample set \#2 has the highest specific surface area and strength properties, which meets the requirements of modern oil-processing catalysts.

- The first series of samples are inferior in qualities due to the negative effect of the heterogeneous phase composition.

The doping of pore-forming additives in the structure of pseudo-boehmite will make it possible to obtain a bidisperse support system from which a highly efficient catalyst can already be obtained.

The next step is to conduct morein-depth studies using all technological methods to transform the available raw aluminum hydroxides into anhydrous porous systems to determine their potential competitiveness and ability to act as supports with improved texture and acid-base properties, and the final efficiencyof new HDS catalysts should be confirmed through of industrial-scale testing.

This work was carried out as part of the State Assignment "Development of scientific foundations of innovative technologies for processing heavy hydrocarbon raw materials into environmentally friendly motor fuels and new carbon materials with controlled macro- and microstructural organization of mesophase". The study was conducted with the involvement of the laboratory base of the Center for Collective Use of Saint Petersburg Mining University.

\section{References}

1. J. Anchita HYDRO-IMP Technology for Upgrading of Heavy Petroleum. Journal of Mining Institute, 224, 229-234 (2017)

2. N. K. Kondrasheva, D. O. Kondrashev Modern hydroprocesses for the synthesis of high-quality low-viscous marine fuels. Catalysis in Industry, 9(1), 1-9 (2017)

3. Y. Ji et al. Promoting effects in hydrogenation and hydrodesulfurization reactions on the zirconia and titania supported catalysts. Applied Catalysis A: General, 257(2), 157- 
164 (2004)

4. A. A. Pavlovich, V. A. Korshunov, A. A. Bazhukov, N. Ya. Melnikov Assessment of the strength of a rock mass in the development of deposits by an open method. Journal of Mining Institute, 239, 502-509 (2019)

5. G. M. Penkov, D. A. Karmansky, D. G. Petrakov Simulation of a fluid influx in complex reservoirs of Western Siberia. Topical Issues of Rational Use of Natural Resources: Proceedings of the International Forum-Contest of Young Researchers. April 18-20. St. Petersburg. Russia, 119 p. (CRC Press, 2018)

6. A. G. Pevneva, G. Penkov, M. D. Bakiev On designing a computational experiment system for various engineering interpretations of a global optimization problem. ARPN Journal of Engineering and Applied Sciences, 12, 1219-1225 (2017)

7. X. Wang et al. Synthesis of NiMo catalysts supported on mesoporous Al2O3 with different crystal forms and superior catalytic performance for the hydrodesulfurization of dibenzothiophene and 4,6-dimethyldibenzothiophene. Journal of Catalysis, 344, 680-691 (2016)

8. L. Zhang et al. CoMo catalyst on zeolite TS-1 nanorod assemblies with high activity in the hydrodesulfurization of 4.6-dimethyldibenzothiophene. Journal of Catalysis, 359, $130-142$ (2018)

9. I. Vázquez-Garrido et al. Effect of support on the acidity of $\mathrm{NiMo} / \mathrm{Al} 2 \mathrm{O} 3-\mathrm{MgO}$ and $\mathrm{NiMo} / \mathrm{TiO} 2-\mathrm{Al} 2 \mathrm{O} 3$ catalysts and on the resulting competitive hydrodesulfurization/hydrodenitrogenation reactions. Fuel, 236, 55-64 (2019)

10. W. S. MiLlman, M. CRESPIN, A. C. CIRILlO, JR., A. W. K. HALL The Surface Chemistry of Reduced Molybdena-Alumina Catalysts. JOURNAL OF CATALYSIS, 60 , 404-416 (1979)

11. R. H. Ebel, D. P. Spitzer, W. E. Bambrick Hydrodesulfurization catalysts based on supports prepared from rehydratable alumna, (USA, 1978)

12. M. Del Arco et al. Surface species formed upon supporting molybdena on alumina by mechanically mixing both oxides. Journal of Catalysis, 48-57 (1993)

13. P. A. Nikulshin Molekulyarnyj dizajn katalizatorov gidroochistky na osnove geteropolisoedinenij helatonov i zauglerozhennyh nositelej. dis. ... dok. him. Nauk, 5075 (Samara, 2015)

14. D. Laurentiet al. Intrinsic potential of alumina-supported CoMo catalysts in HDS: Comparison between $\gamma \mathrm{c}, \gamma \mathrm{t}$, and $\delta$-alumina. Journal of Catalysis, 297, 165-175 (2013)

15. V. M. Sizyakov, V. Y. Bazhin, E. V. Sizyakova Feasibility study of the use of nepheline-limestone charges instead of bauxite. Metallurgis, 59(11), 1135-1141 (2016)

16. A. Tanimu, K. Alhooshani Advanced Hydrodesulfurization Catalysts: A Review of Design and Synthesis, Energy and Fuels, 33(4), 2810-2838 (American Chemical Society, 2019)

17. R. Geoffrey, M. K. Wilson US Patent - Hydrodesulfurization catalyst and process for producing the same, (USA, 1977)

18. A. L. Dicks et al. A study of relationships between pore size distribution, hydrogen chemisorption, and activity of hydrodesulphurisation catalysts. Journal of Catalysis, 72(2), 266-273 (1981)

19. J. Leyrer et al. Structure and surface properties of supported oxides. Materials Chemistry and Physics, 13(3-4), 301-314 (1985)

20. H. Shimada et al. Support effect on the catalytic activity and properties of sulfided molybdenum catalysts. Journal of Catalysis, 110(2), 275-284 (1988)

21. T. Kazushi Usui, K. O. Fujikawa Catalyst composition for hydrodesulfurization of hydrocarbon oil and process for producing the same, (1993)

22. F. Rashidi et al. Ultradeep hydrodesulfurization of diesel fuels using highly efficient nanoalumina-supported catalysts: Impact of support, phosphorus, and/or boron on the 
structure and catalytic activity. Journal of Catalysis, 299, 321-335 (2013)

23. C. J. Pereira, L. Hegedus. Catalyst with high geometric surface area alumina extrudate and catalyst with high geometric surface area, (USA, 1985)

24. Rinaldi, N. et al. 2009. Preparation of Co-Mo/B2O3/A12O3 catalysts for hydrodesulfurization: Effect of citric acid addition. Applied Catalysis A: General, 360(2), 130-136

25. Usman et al. The effect of boron addition on the hydrodesulfurization activity of MoS2/Al2O3 and Co-MoS2/Al2O3 catalysts. Journal of Catalysis, 227(2), 523-529 (Academic Press, 2004)

26. Usman et al. Effect of boron addition on the surface structure of Co-Mo/Al2O3 catalysts. Journal of Catalysis, 247(1), 78-85 (Academic Press, 2007)

27. J. P. R. Vissers et al. Carbon-covered alumina as a support for sulfide catalysts, Journal of Catalysis, 114(2), 291-302 (Academic Press, 1988)

28. O. V. Klimov et al. CoMo/Al2O3 hydrotreating catalysts of diesel fuel with improved hydrodenitrogenation activity. Catalysis Today, 307, 73-83 (Elsevier B.V., 2018)

29. T. N. Vdovina, A. S. Belyj, M. D. Smolikov Raspredelenie aktivnogo komponenta po poram raznogo razmera v strukture oksidnyh nositelej. Kinetika i kataliz, 31(4), (1990)

30. T. Kamo Method of preparing catalysts for hydrogenation of hydrocarbon oil. (USA, 1993)

31. A. Ishihara, M. Nomura, T. Kabe Hydrodesulfurization of Dibenzothiophene Catalyzed by Supported Metal Carbonyl Complexes (Part 2) Hydrodesulfurization Catalysts Prepared from Alumina-supported Anionic Ruthenium Carbonyls. Journal of The Japan Petroleum Institute, 37(3), 300-310 (1994)

32. A. Ishihara, M. Nomura, T. Kabe Hydrodesulfurization of Dibenzothiophene Catalyzed by Supported Metal Carbonyl Complexes (Part 2) Hydrodesulfurization Catalysts Prepared from Alumina-supported Anionic Ruthenium Carbonyls. Journal of The Japan Petroleum Institute, 37(3), 300-310 (1997)

33. S. Eijsbouts, L. C. A. Van Den Oetelaar, R. R. Van Puijenbroek MoS2 morphology and promoter segregation in commercial Type $2 \mathrm{Ni}-\mathrm{Mo} / \mathrm{Al} 2 \mathrm{O} 3$ and $\mathrm{Co}-\mathrm{Mo} / \mathrm{Al} 2 \mathrm{O} 3$ hydroprocessing catalysts. Journal of Catalysis, 229(2), 352-364 (2005)

34. K. A. Nadeina et al. A Catalyst for Selective Hydrotreatment of Non-Prefractionated FCC Gasoline. Kataliz v promyshlennosti, 16(6), 57-64 (2016)

35. V. V. Danilevich et al. Novel eco-friendly method for preparation of mesoporous alumina from the product of rapid thermal treatment of gibbsite. Superlattices and Microstructures, 120, 148-160 (Elsevier, 2018)

36. Y. V. Vatutina et al. Influence of the phosphorus addition ways on properties of CoMo-catalysts of hydrotreating.Catalysis Today, 329, 13-23 (Elsevier, 2019)

37. V. K. Holl Genezis i svojstva molibden alyuminievyh i rodstvennyh katalizatorov. Problemy sovremennogo kataliza. Trudy mezhdunarodnoj konferencii pamyati G.K. Boreskova, (Novosibirsk, 1988) 